\title{
La memoria histórica de Cartagena en el discurso turístico
}

Freddy Ávila Domínguez ${ }^{1}$

Universidad de Cartagena

\section{Resumen}

Folletos, guías, catálogos y demás textos turísticos representan a Cartagena como una ciudad colonial anclada en un pasado mítico. En el presente artículo, el análisis discursivo del texto "Notas de Historia" evidencia que la memoria histórica que reconoce el discurso turístico es la que refiere el pasado hispánico de la ciudad. El examen de los diversos elementos de la narración (acción, personajes y ambiente) demuestra que el texto sólo aborda acontecimientos situados entre los siglos XVI y XVIII, invisibilizando otras memorias que tuvieron lugar antes y después de este período. Los referentes asociados a lo indígena y lo africano son prácticamente inexistentes, y cuando aparecen, vienen acompañados de palabras, formas verbales y significados que inferiorizan. Se trata, entonces, de una memoria

\section{Abstract}

Leaflets, guides, catalogs and other tourist texts present Cartagena as a colonial city anchored in a mythical past. In the present article the discursive analysis of the text "Notes of History" gives evidences that the historical memory recognized by tourist speech is the one that refers to the Hispanic past of the city. Examining diverse elements of the narration (action, characters and atmosphere) it is demonstrated that the text only approaches events placed between the XVI and XVIII centuries, invisibilizing other memories that took place before and after this period. The referents associated to the indigenous thing and the African thing are practically nonexistent and, when they appear, they are joined with words, verbal forms and meanings that minimize. It is, then, a historical memory that coincides with the memory of the

\footnotetext{
${ }^{1}$ Profesional en Lingüística y Literatura, Facultad de Ciencias Humanas, Universidad de Cartagena. Actualmente es profesor en el área de lingüística en la misma Universidad y candidato a Doctor por la Universidad de Salamanca en Análisis del Discurso y sus Aplicaciones. Correo-e: faviladominguez@gmail.com
} 
histórica que coincide con la memoria de la historiografía tradicional, la cual ignora y minimiza el papel de los actores populares, y en general, de las poblaciones que no acreditan ascendenciaapariencia europea.

Palabras clave: discurso turístico, texto de historia, narración, memoria histórica. traditional historiography, which ignores and minimizes the role of the popular actors and in general of the people who don't credit European origin-appearance.

Keywords: tourist speech, history text, narration, historical memory.

Durante los últimos años, los destinos del Caribe han redefinido su imagen turística con el propósito de posicionarse como lugares que ofrecen algo más que sol y playa. Camila Bernal y Paola Quintero (2005) llegan a esta conclusión después de examinar la presentación de los destinos turísticos del Caribe hispano en FITUR, en las versiones 2005 y 2006, así como en los catálogos de los mayoristas y las páginas oficiales de promoción de algunos de estos países. Para estas autoras, la intención "Caribe es más..." se encuentra implícita en la mayor parte de las campañas promocionales de la región, respaldando la introducción de nuevos productos, de manera especial aquellos relacionados con la historia, la identidad y la cultura de la gente local (Bernal \& Quintero, 2005: 74).

Estos productos, a la vez que diversifican la oferta, la ajustan a las variaciones que experimenta la demanda. Con la emergencia del turismo cultural, cada vez es mayor el número de turistas que no se conforma sólo con las tradicionales imágenes de consumo asociadas al Caribe: playas de arena blanca, palmeras, etc. Ahora, mucho más que antes, los desplazamientos también están motivados en el deseo de aprovechar la estancia para participar en un festival de música, teatro o gastronomía; conocer la historia del lugar o aspectos de su patrimonio; tener una aproximación a los recursos intangibles. La complementación del turismo de sol y playa con el cultural es una apuesta atractiva, tanto para los destinos posicionados como para los que están en proceso de consolidación. Cartagena, que hace parte de este último grupo, no es ajena a este proceso, incluso, en su caso el componente histórico-cultural ha pasado a ocupar el primer lugar dentro de la oferta:

[...] hasta hace unos años se promocionó como un destino exótico, dotado de playas de arena blanca con un atractivo histórico cultural complementario. Hasta el 2003 el destino 
se incluía en los catálogos de los mayoristas bajo la marca Caribe, al lado de República Dominicana, Cuba, Puerto Rico, entre otros. Sin embargo la imagen Caribe en lo turístico no correspondía a la realidad, pues sus playas no se asemejan a la de las fotos de 'playa y palmera' que identifican el producto Caribe en los catálogos. (Bernal \& Quintero, 2006: 76)

En la actualidad, la ciudad privilegia el producto cultural, poniendo a su disposición el capital simbólico resultante de su reconocimiento como Patrimonio dela Humanidad y todoslos recursos monumentales con que cuenta, dada su condición de ciudad histórica. La arquitectura militar y religiosa es, en este contexto, el componente patrimonial sobre el que basa su identidad, y por lo tanto, la proyección de su imagen. Al día de hoy, con más de 475 años de existencia, la ciudad conserva la mayor parte de las construcciones de carácter militar construidas durante la Colonia para su defensa. Período en el que, además de ser uno de los más importantes puertos para el comercio, fue la plaza fuerte más importante de España en el Nuevo Mundo y la segunda de este tipo en el Caribe.

El Instituto de Patrimonio y Cultura de Cartagena -IPCC- informó en el 2004 que Cartagena posee "cerca de dos mil construcciones civiles y religiosas en pie, más de 4.5 kilómetros lineales de murallas, con cerca de 50.000 metros cuadrados de plataforma o área transitable, y cerca de 15 hectáreas de áreas perimetrales de murallas, 1.600 metros lineales de escollera de la marina, 3.200 metros lineales de la escollera de Bocagrande, y un sinnúmero de bienes muebles que reposan en distintas colecciones privadas y museos".

Todos estos recursos cumplen una función turística, fundamentada en la valoración del componente histórico. Este énfasis es desarrollado ampliamente en las publicaciones de las instituciones y empresas del sector: "Disfrute un recorrido por la fascinante historia de Cartagena [...]", "Descubre tu propia historia", "Cartagena de Indias. Un centro Históricoy Cultural para quetus congresos hagan historia”,"ciudadllena de historia”, "Cartagena de Indias es historia [...] y es historia”, "entra a la historia", "donde a cada paso hay una cita con la historia", "En Cartagena la historia se encuentra a cada esquina [...]". Si en algo coinciden estas expresiones es en el propósito de representar a Cartagena como un lugar para la memoria. Pretenden activar la dimensión temporal del desplazamiento, convirtiéndolo en una oportunidad para volver al pasado. Los textos turísticos que promocionan la ciudad reproducen este leitmotiv, por lo general a través de la elección de las imágenes que ilustran sus portadas o páginas y de los mismos contenidos, los cuales destacan acontecimientos de la historia de la ciudad. Lo más frecuente 
es que éstos aparezcan en la primera página de las publicaciones, bajo los títulos de Historia o Historia y Cultura.

Tomando como punto de partida esta relevancia de los contenidos históricos en la actividad turística local, a continuación realizamos el análisis del texto "Notas de Historia". Este escrito, de la autoría de Miguel Camacho Sánchez, aparece en la página siete de la guía turística Cartagena corazón del Caribe, publicada en el año 2005 por la Corporación Turismo Cartagena de Indias, entidad que coordina en Cartagena las actividades relacionadas con el turismo. El análisis del texto nos permitirá determinar cuál es la puesta en escena que realiza el discurso turístico de la historia de la ciudad, qué aspectos de la memoria histórica visibiliza y, en definitiva, qué lugar ocupan en ella los habitantes que la poblaron en el pasado. Teniendo en cuenta el enfoque crítico que adopta el presente trabajo, retomamos para su desarrollo el siguiente planteamiento de Raúl Román (2001: 28): "Una cosa es el proceso histórico y otra diferente es el discurso de la historia. Hay conflictos sociales en el proceso histórico y -tambiénhay conflictos sociales en la memoria".

Este planteamiento es especialmente pertinente para el caso de Cartagena, donde dos escuelas historiográficas contrapuestas han elaborado una interpretación distinta de algunos sucesos fundacionales de la historia urbana, privilegiando cada una, desde su perspectiva, ciertos períodos, sucesos, actores y procesos. Para Elisabeth Cunin (2003), es claro que,

\section{[...] si la historiografía tradicional de Cartagena realza el papel de las elites e insiste en los acontecimientos de carácter político, destacando su dimensión heroica, en cambio, el interés de los trabajos contemporáneos gira alrededor de planteamientos socioeconómicos y acentúa el papel de las clases populares. Antes se reducían las poblaciones 'negras' y 'mulatas' a papeles mínimos y subordinados, pero ahora son colocados en los primeros lugares de la historia de la ciudad. (Cunin, 2003: 149)}

Hasta la fecha, como lo han señalado varios estudiosos (Solano, 997; Múnera, 2001; García Usta, 2005), la escuela historiográfica que ha moldeado la memoria colectiva de la ciudad es la tradicional. ¿Adopta el discurso turístico su interpretación-narración de la historia? ¿Reproduce la exclusión? ¿Ayuda a consolidar una memoria colectiva que niega e invisibiliza lo indígena, lo africano y lo popular? Las categorías de análisis que se privilegiarán en la descripción e interpretación del texto "Notas de Historia" (ver recuadro con la trascripción del texto) son las de género y modalidad textual, en 
particular lo que tiene que ver con la narración y sus elementos. No obstante, en la medida que asumimos que un auténtico análisis del discurso articula tres dimensiones -lenguaje en uso, cognición e interacción- permanentemente estableceremos relaciones entre ellas, mostrando, por ejemplo, cómo en razón de las ideas o creencias se actualizan determinadas relaciones sociales y/o estructuras verbales.

\section{Texto de historia, pero no en sentido estricto}

Atendiendo a la definición de género propuesta por Luis Cortés y Matilde Camacho, en términos de "agrupación abstracta de textos o discursos que cumplen funciones sociales similares y tienen ciertas características formales en común" (2003: 80), clasificamos el texto "Notas de Historia" en la categoría de texto de historia. No obstante, como se indica en el título que da nombre a esta sección, pensamos que esta clasificación no aplica en sentido estricto. Revisemos primero las razones que hacen de él un texto de historia.

El hecho de que su autor lo clasifique desde el título como un escrito de carácter histórico constituye la razón más evidente para considerarlo como tal. Con ello, a la vez que lo identifica como perteneciente a un género determinado, lo opone a otro tipo de textos que cumplen una función social diferente y presentan sus propios rasgos formales. La sola mención de la palabra historia, que en su primera acepción significa "narración y exposición narración. La narración histórica cuenta hechos pasados, de ahí su preferencia por el pretérito indefinido, tiempo verbal que predomina en "Notas de Historia" ("descubrió la totalidad", "prohibió edificar", etc.).

En conclusión, tres razones sustentan la clasificación de "Notas de Historia" en el género texto de historia: la propia clasificación que realiza su autor en el título, el criterio de verdad aplicado a los acontecimientos que se cuentan, y por último, su manifestación narrativa, modalidad que en la narración histórica privilegia el empleo de la tercera persona y formas verbales de tiempo pasado. Es importante aclarar, tal como se deduce del título, que "Notas de Historia" no es un texto de historia habitual, tipo libro, sino un texto menor, próximo a la síntesis o a la reseña histórica. Esta particularidad, además de ser plenamente compatible con la clasificación de género ya enunciada, es una muestra de las condiciones de producción en las que se gesta el texto: el hecho de que sea elaborado para una guía turística define su breve extensión y la selección de contenidos, puesto que visitantes y turistas son los principales destinatarios. 


\section{Notas de Historia ${ }^{2}$}

[1]Bienvenido a Cartagena de Indias -de Indias para no confundirla con la de España- en donde deseamos pase usted una grata estadía. Esta noble villa de castillos, muros, sol y mar, fue otrora víctima de asoladoras incursiones por parte de los piratas que infestaban el Mar Caribe, ya que de su rada salían los galeones cargados de oro y riqueza para la poderosa España "en cuyo dominio no se ocultaba el sol" y a su puerto llegaban cargamentos costosísimos de esclavos, mercancías preciosas y útiles que en sus bodegas eran almacenados.

[2]En su segundo viaje Cristóbal Colón, en 1498, pasó cerca de estas playas sin detenerse. [3] Posteriormente en 1505, Don Rodrigo de Bastidas descubrió la totalidad del litoral Atlántico; pero fueron Peralonso Núñez y Cristóbal Guerra quienes anclaron por primera vez en la bahía que llamaron "Cartagena".

[4] Pedro de Heredia a mediados de 1533 decidió sentar reales en el villorrio indígena de Calamarí que más tarde transformado en próspera ciudad se llamaría Cartagena.

[5]Este insignificante poblado, mejorado y ampliado por conquistadores, mercaderes y aventureros, quedó reducido a cenizas en 1522; razón por la cual, De Heredia, ya gobernador, prohibió edificar con materiales que no fueran ladrillos, tejas, calicanto y piedras.

[6]Contaba Cartagena apenas diez años como pujante villa española, cuando comenzó la primera serie de ataques, saqueos y piratería.

[7] El primero de los aventureros que asaltaron a Cartagena, fue el temido francés Roberto Baal, seguido por John Hawkins y los hermanos Juan y Martín Coté. Con la incursión de Sir Frances Drake quedó clausurado este primer periodo de prueba para su supervivencia.

[8] Fieles testigos del poder ibérico son los fuertes, las baterías, los fortines y los castillos, en cuyas construcciones se combinan el ingenio de los arquitectos españoles e italianos con el trabajo y el sacrificio de los esclavos traídos de África a América para trabajar como bestias de carga.

${ }^{2}$ Transcripción del texto “Notas de Historia”, escrito por Miguel Camacho Sánchez y tomado de la pagina 7 de la guía turística Cartagena Corazón del Caribe, publicada en el año 2005 por la Corporación Turismo Cartagena de Indias. 


\section{1. ¿Por qué no texto de historia en sentido estricto?}

Una vez expuestas las razones que sustentan la pertenencia del escrito al género texto de historia, pasamos a aclarar por qué pensamos que, en su caso, no aplica esta clasificación en sentido estricto. La discusión es importante, porque pone en evidencia que en el análisis del discurso las diversas categorías de análisis (verbales y no verbales) se cruzan a menudo, influyendo unas sobre otras. El punto de partida desde el cual abordaremos la discusión de texto de historia en sentido estricto o no, es el siguiente: "[...] el libro de texto de historia, en que el autor no quisiera manifestar su opinión, su comentario o interpretación de los hechos que narra como si él no los narrara, pudiera al menos en hipótesis ajustarse a la definición estricta de 'historia"' (Lozano, 1987: 188). Tal como se desprende de la cita, para este autor "libro de historia" en sentido estricto es aquel en el que el historiador, o quien haga las veces de historiador, no deja su huella, a la manera de comentario, opinión e interpretación en los hechos narrados. Esta toma de distancia funciona a favor del criterio de "la verdad de lo que se cuenta", en la medida que permite al texto de historia ganar identidad, marcar clara diferencia con las obras de ficción.

Esta pretensión de "dejar al referente hablar solo" no aplica en "Notas de Historia", en la medida que el narrador no se limita a contar los hechos, sino que, permanentemente, a la manera del editorialista de un periódico, interviene o se implica en ellos evaluándolos. Así se puede ver en los siguientes fragmentos: "Esta noble villa de castillos [...] fue víctima de asoladoras incursiones [...] cargados de oro y riqueza para la poderosa España". Los adjetivos en cursiva evidencian el uso de modalizaciones, entendidas como "la expresión verbal o no verbal de la visión del locutor respecto al contenido de su enunciado" (Calsamiglia \& Tusón, 1999). Del mismo modo que en estas muestras del párrafo uno, esta tendencia se repite a lo largo del texto marcada por el uso de adjetivos -insignificante (párrafo cinco), temido (párrafo siete)- y otro tipo de modalizaciones que revelan la presencia del narrador: "Bienvenidos a Cartagena de Indias -de indias para no confundirla con la de España- en donde deseamos (que) pase usted una grata estadía" (párrafo uno).

Nótese que la forma verbal deseamos de presente simple del plural involucra al narrador, quien, a través del pronombre personal usted, apela de manera explícita al destinatario. Lo hace omitiendo la tercera persona y la objetivación, formas que caracterizan a la narración histórica. Para Lozano, "en la narración rigurosamente histórica podemos encontrar, como rasgo característico, sólo formas de tercera persona: ningún /yo/ aparece en el texto y, por consiguiente, 
como hemos dicho ningún /aquí/ o /ahora/: los hechos y acontecimientos son enunciados tal como se han producido en su aparecer en el horizonte de la historia" (Lozano, 1987: 188).

\subsection{Rasgos pragmalingüísticos del discurso turístico en el texto de historia}

La constante intervención del narrador en lo narrado está directamente relacionada con la inclusión del texto "Notas de Historia" en una publicación orientada a la promoción turística. Ésta característica de la situación comunicativa le impone, entre otros aspectos, propósitos persuasivos, de modo que termina "asimilando" rasgos, sobre todo pragmalingüísticos, propios del discurso turístico:

a. Orientación al interlocutor: el texto inicia con un saludo de bienvenida (Bienvenidos a Cartagena) que, desde el punto de vista de lo que se conoce como esquema o superestructura, es ajeno al texto de historia, mucho más si es escrito. Este acto de dar la bienvenida, además de marcar la presencia del interlocutor, pues se le da la bienvenida a alguien, constituye una forma de cortesía lingüística.

b. Uso del nosotros/as para aumentar la sensación de participación: el acto de dar la bienvenida lo realiza un "nosotros", presente en la forma verbal deseamos. La elección de esta forma hace suponer que el autor del texto se identifica como miembro de un grupo o institución. ¿Cuál es este grupo o institución? Teniendo en cuenta que la guía turística es editada por la Corporación Turismo Cartagena de Indias, lo más posible es que hable a nombre de ella. 0 , quizá, de un nosotros indefinido, que representa a los habitantes de Cartagena. De ser así, el escrito asume la vocería de los habitantes de la ciudad, trasmitiendo la idea de que este colectivo le brinda hospitalidad.

c. Uso de formas de tratamiento adecuadas al interlocutor para cuidar fallas en la distancia social: el uso del pronombre deíctico de segunda persona usted indica respeto, su preferencia frente al tú, que indica mayor grado de confianza, constituye una forma de mantener o cuidar la distancia social. El visitante o turista es tratado con respeto y amabilidad, pues no se le conoce y puede sentir violada su intimidad con el empleo de formas de tratamiento que sugieran relaciones horizontales.

\footnotetext{
${ }^{3}$ Ver, al respecto, Moreno y Tuts (2004).
} 
La presencia de los anteriores rasgos pragmalingüísticos propios del discurso turístico en "Notas de Historia" demuestra que en su interior se alternan, en relación polifónica, dos formas discursivas: la que corresponde al texto de historia, que apuesta por la objetivación y la tercera persona, y la que corresponde al discurso turístico, que pone en escena, en tanto enunciación discursiva, a los sujetos de la enunciación. En esta dirección, el discurso turístico apela al usted, pues el visitante es su objetivo.

\section{Historia, narración y algo más}

Con motivo de la clasificación del texto de estudio en un tipo de género, en páginas anteriores señalamos las relaciones entre el texto de historia y la narración como modalidad textual. De hecho, sugerimos que la Historia, sea cual sea la manifestación que adopte, no existe sin narración. A continuación, tomando como modelo de análisis los elementos de la narración señalados por Miriam Álvarez (2006), pasamos a describir la narración del modo como se presenta en "Notas de Historia":

\subsection{Acción}

En el texto los hechos o acontecimientos narrados se organizan en torno a cuatro realidades de orden histórico:

a. Descubrimiento de Cartagena en el contexto de América y el mar Caribe: párrafos dos y tres.

b. Su conquista y colonización por españoles: párrafos cuatro y cinco.

c. Ataques a la ciudad por piratas y aventureros: párrafos seis y siete.

d. Construcción de murallas, castillos y fuertes: párrafo ocho

El esquema o modo de organización del discurso que adopta el texto para presentar los acontecimientos es el siguiente:

a. Bienvenida: categoría de base pragmática que revela la forma en que el texto es permeado por el discurso turístico, sobre todo en lo relacionado con la "orientación hacia el interlocutor". Puede verse en las tres primeras líneas del párrafo uno (Bienvenidos a Cartagena [...] estadía). 
b. Presentación de la acción, de los personajes y del ambiente: en "Notas de Historia" el narrador realiza una presentación general de los acontecimientos que serán objeto de la narración. Esta categoría funciona a la manera de un resumen que ofrece las características del tema a tratar. Puede verse en el párrafo uno, después de la categoría anterior (Esta noble villa de castillos [...] que en sus bodegas eran almacenados).

c. Nudo o desarrollo de los hechos: concebida como la parte central de la trama, esta categoría se extiende desde el párrafo dos al siete. Recurriendo a un procedimiento de aceleración de la historia, el narrador da cuenta de quiénes fueron los primeros conquistadores en arribar a la bahía que más tarde se llamaría Cartagena. De igual forma, relata su transformación como ciudad a mediados hacia 1550 , gracias al trabajo de conquistadores, mercaderes y aventureros. El desarrollo de los hechos alcanza el mayor grado de tensión en el párrafo seis, donde el narrador refiere los ataques, saqueos y piraterías de que es víctima la ciudad.

d. Desenlace o solución de la situación planteada. Esta categoría aparece al final del párrafo siete, allí el narrador cuenta que con la incursión de Sir Francis Drake termina el primer período de ataques a la ciudad.

e. Evaluación: el narrador ofrece su valoración o interpretación de los hechos. Esta valoración destaca el poderío de los españoles en la defensa de la ciudad, que hoy tiene como fieles testigos a los muros, fuertes y castillos.

La descripción del esquema o superestructura textual pone de relieve la existencia de una categoría ajena a la narración histórica escrita: la "Bienvenida", que responde, como dijimos antes, a la "asimilación" que realiza el texto de los rasgos pragmalingüísticos del discurso turístico. Por su orientación al interlocutor es más propia de un guía turístico, que usualmente recurre a ella para efectos de ambientar su interacción con los turistas.

De otro lado, ya en el plano del contenido, la elección de las acciones revela la reducción de la historia de Cartagena a la conquista y la Colonia, pues los acontecimientos narrados sólo cubren el período comprendido entre los siglos XVI y XVIII. Lo que existió antes de la conquista y después de la Colonia no es relevante para el narrador. El texto no realiza, por ejemplo, ninguna mención a la Independencia de Cartagena, a pesar de que ésta es "el acontecimiento más 
importante de la historia de la ciudad, uno de sus 'mitos fundadores'” (Cunin, 2003: 143), y lo más relevante, el referente histórico desde el cual se intenta forjar en el presente la memoria colectiva. En la interpretación de este suceso, la escuela de nuevos historiadores, la alternativa, destaca el elemento racial al situar como protagonistas de la Independencia a los negros y mulatos. En este contexto, Pedro Romero, un mulato, encarna el espíritu libertario de quienes lucharon por ella:

El 11 de noviembre de 1811, los mulatos y negros de Getsemaní impondrían por la fuerza a las élites criollas la declaratoria de la independencia absoluta de Cartagena [...] Pedro Romero, al frente de los Lanceros del Getsemaní y del resto del pueblo de este barrio, asaltó el almacén de armas. Armados de lanzas, fusiles y puñales, sus hombres irrumpieron en el salón donde se encontraba reunida la junta y exigieron que se declarara la independencia de Cartagena. (Múnera, 2001: 196).

$\mathrm{Al}$ desconocer este acontecimiento y a los actores populares que lo hicieron posible, el relato histórico privilegia una memoria extraña, o al menos distante, a la mayor parte de la población. Por lo tanto, reproduce el discurso histórico oficial, el cual, según Sergio Solano,

[...] hizo de la colonización española, en especial de la fundación de ciudades y villas (por ejemplo, Enrique Otero D'costa en su libro Comentos críticos sobre la fundación de Cartagena de Indias), de la cultura ibérica (verbigracia, el libro de Gabriel Porras Troconis Cartagena Hispánica, en el que presenta a los cartageneros del siglo XVIII como personas célibes, abstemios, cuyas noches se les iban rezando el rosario y elevando oraciones al cielo), y de la epopeya emancipadora -en una versión donde la elite criolla es la única protagonista-, los actos fundacionales de la nación colombiana, y al mismo tiempo los temas que concitaban sus pasiones. (1987: 35).

Otras memorias históricas de base popular también son desconocidas. Durante el propio período colonial, por ejemplo, tuvo lugar el cimarronismo, movimiento que planteó resistencia al sistema esclavista. Benkos Biohó, un esclavo africano traído de Guinea, después de fugarse e internarse en el monte, organizó a finales del siglo XVI los primeros palenques. El palenque de San Basilio, símbolo de Independencia para los esclavos fugitivos, alcanzó en 1713, por decreto Real del Rey de España, la libertad. De hecho, es considerado el primer pueblo libre de América. Para las organizaciones "afro" y los afrodescendientes, sobre todo los palenqueros, este acontecimiento 
constituye el más importante referente de identidad. De acuerdo a Cunin,

La lucha de los cimarrones termina entonces cambiando la imagen de lo 'negro': identificado por su relación con al esclavitud, lo malo, lo salvaje y lo inferior, gracias al cimarronismo, se convierte en símbolo de libertad e independencia [...] Los habitantes de San Basilio afirman que el palenque desempeñó un papel fundamental en la formación de Colombia y América Latina. (2003: 248)

Al invisibilizar esta memoria, la narración histórica que difunde el turismo también invisibiliza, en una lógica excluyente, la identidad de quienes se reconocen afrodescendientes. Teniendo en cuenta que en Cartagena más del $80 \%$ de la población pertenece a este grupo étnico (Álvarez, 2007: 12), la negación del elemento "afro", o su tratamiento despectivo, es claramente discriminatorio. Mucho más si se ignora para reivindicar, como sucede en "Notas de Historia", el papel del blanco europeo. Otras memorias vinculadas al elemento étnicoracial, como la indígena y mestiza, también son menospreciadas. En el caso de esta última, la representación inferiorizante es más que evidente, lo indígena aparece asociado al retraso.

\subsection{Personajes}

Conquistadores, mercaderes, aventureros, piratas, ingenieros, arquitectos y esclavos son los personajes que intervienen en "Notas de Historia". En relación con las acciones identificadas en el punto anterior, su participación puede ilustrarse de la siguiente manera:

a. Acciones de descubrimiento: Cristóbal Colón (En su segundo viaje Cristóbal Colón, en 1498, pasó cerca de estas playa), Rodrigo de Bastidas (descubrióla totalidad del litoral Atlántico), Peralonso Núñez y Cristóbal Guerra (anclaron por primera vez en la bahía).

b. Acciones de conquista y colonización: Pedro de Heredia ( $a$ mediados de 1533 decidió sentar reales en el villorrio indígena de Calamarí -y- De Heredia, ya gobernador, prohibió edificar con materiales).

c. Acciones de ataque, saqueo y destrucción: Roberto Baal, John Hawkins, Juan y Martín Coté, Francis Drake (ver párrafo siete). 
d. Acciones de construcción de la defensa: arquitectos españoles e italianos (en cuyas construcciones se combinan el ingenio de los arquitectos españoles e italianos), esclavos africanos (traídos de África a América para trabajar como bestias de carga).

Esta clasificación de los personajes según su participación en los acontecimientos revela el papel que se les asigna en la narración y las diversas relaciones que tejen entre sí. Así, los piratas son personajes antagonistas en cuanto se oponen a los personajes protagonistas y sus acciones; en cambio, los ingenieros y arquitectos que construyen la defensa de la ciudad son personajes auxiliadores o adyuvantes, en tanto prestan sus servicios a los personajes protagonistas para asegurar la seguridad de la misma.

En "Notas de Historia" la actuación de los personajes asigna un papel protagónico a conquistadores y colonizadores españoles, presentados como los responsables de la fundación y progreso de Cartagena. Pedro de Heredia es el personaje de mayor relevancia en la narración; a él se debe que el villorrio indígena de Calamarí deje de ser un insignificante poblado y pase a ser una pujante villa española. Es importante puntualizar que su presentación en el texto viene acompañada de oraciones activas y verbos de acción como "decidir" (decidió sentar reales en) y "prohibir" (prohibió edificar con materiales que no fueran) que destacan su papel de agente.

Frente a este papel protagónico que desempeña Pedro de Heredia, los indígenas y esclavos son prácticamente ignorados, a tal punto que aparecen mencionados en abstracto, sin un nombre propio que les confiera identidad en la narración. En el caso de los indígenas, además de ser apenas aludidos -la historia de Cartagena comienza con el arribo de españoles-, su representación es despectiva, en el sentido que se les asocia con el retraso: habitaban un villorrio: "De villa. m. Despect. Población pequeña y poco urbanizada" (DRAE, 1984); insignificante. La llegada de los españoles determinará la transformación del villorrio en próspera ciudad.

La referencia al negro africano, también marginal, se hace en el marco de la trata (a su puerto llegaban cargamentos costosísimos de esclavos). Si su aporte a la construcción de las murallas consistió en un sacrificio que los llevó a trabajar como bestias de carga, el aporte de los españoles y europeos será de tipo intelectual (se combinan el ingenio de los arquitectos españoles e italianos).

En este orden de ideas, el texto "Notas de Historia" coincide con el relato histórico tradicional. Éste, como recuerda Elisabeth Cunin 
(2003: 150) asigna al negro -lo mismo que al mulato y al indígenapapeles pasivos: "de la historia oficial de Cartagena se destaca que los papeles principales, ordenados cronológicamente, han sido desempeñados por los fundadores de la ciudad, los piratas, los jefes de la armada, los ingenieros que construyeron las murallas, los miembros del Tribunal de la Inquisición [...]".

A diferencia de la descripción que se realiza de conquistadores y colonizadores, marcada por el empleo de oraciones activas y verbos de acción, la descripción de los esclavos se hace recurriendo a estructuras pasivas (los esclavos -que fueron- traídos) que señalan su condición de objeto y no de ejecutor ni mucho menos protagonista de los acontecimientos. Es importante destacar que, en relación con la trata esclavista, el texto no asigna responsabilidad a ningún personaje (a su puerto llegaban cargamentos costosísimos de esclavos traídos de África a América). Para estas acciones, no hay protagonistas, faltan nombres y apellidos.

\subsection{Ambiente}

El lugar donde se desenvuelve la acción y la actuación es Cartagena. El narrador, en la medida que intenta reconstruir su historia, da cuenta de sus transformaciones a lo largo del tiempo con la intención de mostrar que la Cartagena de hoy (noble villa de castillos) es el resultado de procesos históricos. De esta manera, su presentación como escenario la sitúa en diversos momentos o períodos: presentepasado-presente. El primer momento presente se aprecia en el párrafo uno, allí el autor o narrador, apartándose del esquema prototípico de la narración histórica, ofrece un saludo de bienvenida a la ciudad (Bienvenidos a Cartagena [...] deseamos -que-pase usted una grata estadía). Como ya hemos comentado antes a propósito de este aparte, en él la comunicación se desarrolla en tiempo presente y señala la presencia de un Nosotros (deseamos) y un Usted (pase usted) que existen, en un aquí y un ahora, tanto como Cartagena. De hecho, su definición como noble villa de castillos muros, sol y mar corresponde a su promoción actual como destino para realizar turismo cultural y de sol y playa.

El paso de esta Cartagena actual (presente) a la Cartagena de antes (pasado) se produce en el párrafo uno, determinado por el cambio de las formas verbales: del presente simple del indicativo "deseamos", el narrador salta al pretérito indefinido "fue" ("Esta noble villa [...] fue otrora [...]"). De esta forma, introduce a Cartagena como escenario de acontecimientos pasados que tuvieron lugar durante el descubrimiento, la conquista y la colonización de América. La 
perspectiva diacrónica que sigue esta presentación de Cartagena como marco espacial le permite al narrador ofrecer un panorama de sus transformaciones: localizada en el entorno del mar Caribe, la bahía fue descubierta por Peralonso Núñez y Cristóbal Guerra; luego, hacia 1533, Pedro de Heredia se estableció en ella cuando apenas era el villorrio indígena de Calamarí. Este villorrio una vez convertido en próspera ciudad pasó a ser Cartagena, ciudad que, a partir de 1552, comenzó a sufrir sucesivos ataques y saqueos, los cuales determinaron la construcción de su sistema de defensa.

Todas estas transformaciones definen a la Cartagena de antes como un escenario que cambia, en razón de la acción y actuación de los personajes. Los ataques de piratas, motivados por las riquezas que poseía, la convierten en escenario-objeto de deseo (ya que de su rada salían galeones cargados de oro y riqueza para la poderosa España [...] y a su puerto llegaban cargamentos costosísimos [...]). Por lo tanto, Cartagena, además de escenario de los hechos, es representada como el objeto de deseo que dinamiza la historia. Su presentación como escenario actual (presente) vuelve a aparecer en el último párrafo, pues el narrador se refiere a su arquitectura desde el presente (fieles testigos del poder ibérico son los fuertes, las baterías, los fortines y los castillos). El uso de la forma verbal son, correspondiente al presente indicativo de tercera persona del plural, muestra el desplazamiento de la referencia hacia el presente, donde Cartagena nuevamente es caracterizada en función de sus construcciones.

Esta caracterización es compatible con la sobreexposición que se hace de las murallas y los castillos en el discurso turístico, lo que permite concluir que en esta representación presente de la ciudad lo más destacado es su patrimonio arquitectónico, punto de lanza de la publicidad turística. La fotografía del Hotel Caribe que aparece en la parte final del texto -en la parte inicial hay una imagen de Cartagena a finales del siglo XVII-, además de cumplir un propósito promocional, sugiere que Cartagena también es una ciudad moderna que ofrece todas las comodidades para vivir, desde el presente, el pasado.

Por otra parte, el análisis semántico del léxico utilizado por el narrador para referirse a Cartagena indica que la ciudad representada, y por lo tanto, reconocida, es la construida por españoles. Antes de la Conquista y la Colonia, ésta apenas existe como bahía, villorrio indígena e insignificante poblado; luego, gracias a la intervención de conquistadores, comerciantes y aventureros, se transforma en la próspera ciudad que recibiría por nombre "Cartagena". Esta representación del "otro" en términos negativos revela la lógica excluyente del discurso 
turístico, al imponer como memoria colectiva la memoria histórica de las elites, la cual sólo reconoce el legado hispánico e invisibiliza y distorsiona los referentes históricos de la mayor parte de la población, vinculados, de manera especial, al mundo Caribe: a personajes como Pedro Romero y Benkos Biohó; a lo negro, lo mulato y lo mestizo; a la resistencia contra la dominación; al sincretismo y a la hibridación cultural, a lo popular...

De esta forma, la apuesta por el turismo cultural en vez de convertirse en un medio para reforzar las identidades y el tejido social urbano, termina convertida en un instrumento que legitima prácticas discriminatorias y los intereses de los grupos poderosos. A visitantes y turistas se les proporciona una interpretación reduccionista y "maquillada" de la historia de la ciudad que no se corresponde con la verdad histórica.

\section{Bibliografía}

Álvarez, Rubén Darío. (Enero 2, 2007). “El eterno retorno”, El Universal. p. 12 Benach, Nuria \& Sánchez, Fernanda. (1999). "Políticas urbanas y producción de imágenes en la ciudad contemporánea: un análisis comparativo entre Barcelona y Curitiba", en Carrión, Fernando y Wollrad, Dörte (comps.). La ciudad, escenario de comunicación. Quito, Flasco/ Fundación Friedrich Ebert Stiftung/Proyecto latinoamericano de medios de comunicación.

Bernal, Camila, Quintero, Paola \& López, Héctor. (2005). “La competitividad turística de Cartagena de Indias: Análisis del destino y posicionamiento en el mercado", en Serie No 4 de Estudios sobre la Competitividad de Cartagena. Cartagena, Observatorio del Caribe Colombiano, Cámara de Comercio de Cartagena y Colciencias.

Bernal, Camila \& Quintero, Paola. (2006). "Diversificación y cultura: Qué ofrece y cómo se promociona Cartagena de Indias en el mercado nacional e internacional", Coloquio Desarrollo territorial y turismo sostenible: una aproximación a partir de la valorización turística, 1721 de agosto de 2006, Bogotá, Universidad del Externado.

Calsamiglia, Helena \& Tuson, Amparo. (1999). Las cosas del decir. Manual de análisis del discurso. Barcelona: Ariel.

Calvi, María Vittoria. (2006). Lengua y comunicación en el español del turismo. Madrid, Arco/Libros.

Camarero Izquierdo, Carmen \& Garrido Samaniego, María José. (2004). Marketing del patrimonio cultural. Madrid: Pirámide-ESIC.

Cortés Rodríguez, Luis \& Camacho Adarve, Ma Matilde. (2003). ¿Qué es el análisis del discurso? Barcelona: Octaedro-Ediciones Universitarias de Barcelona.

Cunin, Elisabeth. (2003). Identidades a flor de piel. Lo "negro" entre apariencias y pertenencias: categorías raciales y mestizaje en Cartagena (Colombia). Bogotá: Instituto Colombiano de Antropología 
e Historia, Universidad de los Andes, Instituto Francés de Estudios Andinos, Observatorio del Caribe Colombiano.

.(2006). "Escápate a un Mundo... fuera de este Mundo": Turismo, globalización yalteridad. Los cruceros por el Caribe en Cartagena de Indias (Colombia)", en Boletín de Antropología, No 37. Medellín: Universidad de Antioquia, pp. 131-151.

.(2007). "El turismo en Cartagena. Vendo, luego excluyo", en Revista Noventaynueve, № 7. Cartagena, pp. 35-39.

Cunin, Elisabeth \& Rinaudo, Christian. (2005). "Las murallas de Cartagena: entre patrimonio, turismo y desarrollo urbano. El papel de la sociedad de mejoras públicas", en Memorias. Barranquilla: Universidad del Norte.

De Ávila, Orlando. (2008). Políticas urbanas, pobreza y exclusión social en Cartagena: el caso de Chambacú, 1956-1971. Tesis de Grado para optar al título de Historiador, Universidad de Cartagena.

De La Calle Vaquero, Manuel. (2006). La ciudad histórica como destino turístico. Barcelona, Ariel.

Díaz, Leonel. (2005). Superficies, demandas e invenciones: la configuración de un discurso urbano para Cartagena de Indias. Tesis de Grado para optar al título de Profesional en Lingüística y Literatura, Universidad de Cartagena.

Dijk, Teun A. Van. (2000). El discurso como interacción en sociedad. Barcelona: Gedisa.

.(2003). Ideología y discurso. Una introducción multidisciplinaria. Barcelona: Ariel.

.(comp.). (1997). El discurso como estructura y proceso. Estudios sobre el discurso I: introducción multidisciplinaria. Barcelona: Gedisa.

Ejarque, Joseph. (2005). Destinos turísticos de éxito. Diseño, creación, gestión y marketing. Madrid: Pirámide.

Flower, Roger \& Gunther Kress. (1983). "Linguística crítica”, en: Flower Roger, Gunther Kress, Bob Hodge \& Tony Trew. (comps.). Lenguaje y control. México: Fondo de Cultura Económica, pp. 247-285.

García Canclini, Néstor. (1990). Culturas Híbridas. Estrategias para entrar y salir de la modernidad. México: Grijalbo.

García Usta, Jorge. (2005). “Competitividad y cultura: ¿Cómo reforzar la identidad Caribe de Cartagena?”, en Serie № 2 de Estudios sobre la Competitividad de Cartagena, Observatorio del Caribe y Cámara de Comercio de Cartagena.

Gómez Domínguez, Álvaro. (2002). “Turismo cultural y política cultural urbana: posibilidades y divergencia”, en Turismo cultural: el patrimonio histórico como fuente de riqueza. Valladolid, Fundación de Patrimonio Histórico de Castilla y León, pp. 343-363.

González Morante, Anahí; Sánchez García, Isabel \& Sanz Blas, Silvia. (2005). "La imagen como factor clave del comportamiento del turista", en Estudios turísticos, № 165, pp. 57-75.

Gutiérrez Ordóñez, Salvador. (2000). Análisis pragmático de textos publicitarios. Madrid: Arco/Libros.

Gutiérrez Sierra, Edgar. (2006). “Las fiestas de la independencia en Cartagena 
de Indias: reinados, turismo y violencia”, en Cunin, Elisabeth \& Gutiérrez, Edgar. (comps.). Fiestas y carnavales en Colombia. La puesta en escena de las identidades. Medellín: LaCarreta/Universidad de Cartagena/Institut de Recherche pour le Développement.

Halliday, Michael A.K. (1982). El lenguaje como semiótica social. La interpretación social del lenguaje y del significado. México: Fondo de Cultura Económica.

Hernández, Gil-Manuel; Santamarina Campos, Beatriz; Moncusí Ferré, Albert; Rodrigo, María. (2005). La memoria cons-truida. Patrimonio cultural y modernidad. Valencia: Tirant Lo Blanch.

Lemaitre, Daniel. (1949). Historia General de Cartagena, tomos II y III. Cartagena, Editora Bolívar.

Lobo Montero, Pilar. (1998). "La comercialización turística de las ciudades históricas españolas”, en Ería. Revista cuatrimestral de Geografía № 47. Universidad de Oviedo, Departamento de Geografía, pp. 281-298.

Lozano, Jorge. (1987). El discurso histórico. Madrid: Alianza Editorial.

Lozano, Jorge; Peña-Marín, Cristina \& Abril, Gonzalo. (1999). Análisis del discurso. Hacia una semiótica de la interacción textual. Madrid, Cátedra.

Martín Rojo, Luisa; Mạ; Pardo, Laura \& Whittaker, Rachel. (1998). “El análisis crítico del discurso: una mirada indisciplinada", en Martín Rojo, L y R. Whittaker (eds.), Poderdecir. Perspectivas en el análisis crítico del discurso. Madrid: Arrecife-Servicio de Publicaciones de la U.A.M., pp. 9-33

Montoya, Jairo. (1996). "Entre un desorden de lo real y un nuevo orden de lo imaginario: la ciudad como conflicto de memorias”, en Giralfo, Fabio \& Viviescas, Fernando. (comps.). Pensar la ciudad. Bogotá: Tercer Mundo, pp. 69-79.

Múnera, Alfonso. (1998). El fracaso de la nación. Región, clase y raza en el Caribe colombiano 1717-1810. Bogotá: Banco de la República/El Áncora Editores.

Ortíz Cassiani, Javier. (1998). "Modernización y Desorden en Cartagena: 1911-1930", en Calvo Haroldo y MeiselL, Adolfo (comps.). Cartagena de Indias y su historia. Cartagena: Banco de la República/Universidad Jorge Tadeo Lozano, seccional del Caribe.

Palou, Saida. (2006). "La ciudad fingida. Representaciones y memorias de la Barcelona turística”, en Pasos № 1, Revista de turismo y patrimonio cultural, pp. 13-28.

Renkema, Jan. (1999). Introducción a los estudios sobre el discurso. Barcelona: Gedisa.

Rodríguez, Emira; Requena, Karen; Muñoz, José Emilio \& Olarte, María. (2006). "Imagen turística de los países latinoame-ricanos en el mercado español", en Cuadernos de turismo No 17, pp. 189-199.

Román, Raúl. (2001). "Memoria y contramemoria: El uso público de la historia en Cartagena", en Desorden en la plaza. Modernización y memoria urbana en Cartagena. Cartagena: Instituto Distrital de Cultura.

Samudio, Alberto. (2005). Caminando por Cartagena: un recorrido histórico y arquitectónico. Cartagena: Producciones Araújo y Samudio. 
.(2006). "Cartagena veintiún años después de ser declarada patrimonio mundial”, en Memorias, № 6. Barranquilla: Universidad del Norte.

Sánchez Bonett. (2006). "La investigación urbana sobre las ciudades del Caribe colombiano: Estado del arte", en Respirando el Caribe. Memorias del II encuentro de investigadores sobre el Caribe colombiano. Cartagena, Observatorio del Caribe colombiano.

Searle, John R. (1969). Actos de habla. Ensayo de filosofía del lenguaje. Madrid: Cátedra, 1980.

Segovia Salas, Rodolfo. (1998). "Cartagena de Indias: historiografía de sus fortificaciones”, en Calvo, Haroldo; Meisel, Adolfo: Cartagena de Indias y su historia. Cartagena: Editores Espitia.

Serra, Antoni. (2002). Marketing turístico. Madrid: ESIC-Pirámide.

Sierra Anaya, Germán. (1998). Viajeros y visitantes. Una historia del turismo de Cartagena de Indias. 1501-1959. Cartagena de Indias: Heliógrafo Moderno.

Sierra Anaya, Germán; Marrugo Torrente, Dennise \& Quejada Pérez, Raúl. (2004). La actividad del turismo en Cartagena de Indias. Cartagena: Editorial Universitaria.

Solano, Sergio P. (1998). “Un siglo de ausencia: la historiografía cartagenera en el S. XX", en Calvo, Haroldo y Meisel, Adolfo (comps.). Cartagena de Indias y su historia. Cartagena: Banco de la República/Universidad Jorge Tadeo Lozano, seccional del Caribe.

Streicker, Joel. (1997). “Spacial Reconfigurations, Imagined Geographies and Social Conflicts in Cartagena, Colombia", en Cultural Anthropology, vol. 12, № 1, pp. 109-128.

Vidal, Claudia. (1998). Los inicios de la industria turística en Cartagena, 1900-1950. Cartagena de Indias. Tesis de Grado para optar al título de Historiadora, Universidad de Cartagena.

Wodak, Ruth \& Meyer, Michael. (comps.) (2001). Métodos de análisis crítico del discurso. Barcelona: Gedisa.

Zapatero, Juan Manuel. (1979). Historia de las fortificaciones de Cartagena de Indias. Madrid: Ediciones Cultura Hispánica del Centro Hispanoamericano de Cooperación y Dirección General de Relaciones Culturales del Ministerio de Asuntos Exteriores.

Zuleta J. \& Jaramillo, Luis Alberto. (2006). "Cartagena de Indias, impacto económico de la zona histórica”, en Colección Serie Economía y Cultura, № 13. Bogotá: Convenio Andrés Bello y Corporación Centro Histórico de Cartagena de Indias, pp. 184-190. 
